\title{
QBO effects on Antarctic mesospheric winds and polar vortex dynamics
}

\author{
E. A. K. Ford, ${ }^{1}$ R. E. Hibbins, ${ }^{1}$ and M. J. Jarvis ${ }^{1}$ \\ Received 9 July 2009; revised 15 September 2009; accepted 23 September 2009; published 23 October 2009.
}

[1] A dynamical link is demonstrated between the equatorial quasi-biennial oscillation (QBO) and highlatitude mesospheric zonal winds recorded by an Imaging Doppler Interferometer (IDI) at Halley, Antarctica. Above $\sim 80 \mathrm{~km}$ eastward winds in winter (an extension of the polar vortex into the mesosphere) are strengthened under easterly $50 \mathrm{hPa}$ QBO conditions. This is similar to the Holton-Tan effect in the stratosphere but working in opposition. The weak winter time zonal winds are shown to differ by up to $2.6 \mathrm{~m} / \mathrm{s}$ dependent on QBO phase. In spring, zonal winds are most strongly correlated with the equatorial $25 \mathrm{hPa}$ QBO and are significantly more westerly in November, an extension of the QBO response in the stratosphere below. It is suggested that QBO modulation of the vortex winds in the Antarctic mesosphere is dependent on planetary-wave activity from the Antarctic in winter and Arctic in spring. Citation: Ford, E. A. K., R. E. Hibbins, and M. J. Jarvis (2009), QBO effects on Antarctic mesospheric winds and polar vortex dynamics, Geophys. Res. Lett., 36, L20801, doi:10.1029/ 2009GL039848.

\section{Introduction}

[2] The Quasi-Biennial Oscillation (QBO) is the dominant dynamical phenomenon in the equatorial stratosphere, and is characterised by a descending pattern of winds which, at any fixed altitude, exhibits repeated switching between easterly and westerly with $\sim 28$ month cycling period. The interaction of the QBO with gravity waves and planetary waves generates QBO-like effects in the equatorial mesosphere (MQBO) [e.g., Burrage et al., 1996], in the extra-tropical stratosphere [e.g., Dunkerton and Baldwin, 1991; Baldwin and Dunkerton, 1998] and in the mid and high-latitude mesosphere and lower thermosphere (MLT) [e.g., Jacobi et al., 1996; Hibbins et al., 2007]; although Baumgaertner et al. [2005] did not find a significant correlation between Scott Base $\left(78^{\circ} \mathrm{S}, 167^{\circ} \mathrm{E}\right)$ MLT mean winds and the QBO. Both the QBO and its dynamical and chemical global interactions are reviewed thoroughly by Baldwin et al. [2001].

[3] Through analysis of horizontal winds at $95 \mathrm{~km}$ altitude derived from the SuperDARN radar at Halley $\left(76^{\circ} \mathrm{S}, 27^{\circ} \mathrm{W}\right)$, Antarctica, Hibbins et al. [2007] showed a modulation of the semidiurnal tide related to the QBO. They suggested that this modulation was due to the propagation of planetary waves from the troposphere in the winter hemisphere to the mesosphere in the summer hemisphere, being either blocked or allowed under easterly or westerly equato-

${ }^{1}$ British Antarctic Survey, Cambridge, UK.

Published in 2009 by the American Geophysical Union. rial MQBO conditions respectively. Hibbins et al. [2009], again using SuperDARN wind measurements, but this time from both the Arctic and Antarctic, to further examine this hypothesis studied the planetary wave activity itself. This supported the process of significant inter-hemispheric propagation of planetary waves from the winter to the summer hemisphere with gating in the equatorial region dependent upon the phase of the MQBO.

[4] Lower down, stratospheric planetary wave activity is also affected by the phase of the QBO in the equatorial stratosphere through QBO-dependent changes in the zerowind line which guides vertical planetary wave propagation. Observational studies suggested a colder, stronger polar winter vortex during westerly QBO and a more disturbed, warmer, polar vortex during easterly QBO. Holton and Tan [1980] explained this as due to movement of the zero-wind line further away from the equator to the subtropics of the winter hemisphere under easterly compared to westerly QBO. This latitudinally narrows the region through which vertically-propagating stationary planetary waves from the extratropical troposphere can travel, because they can only propagate through a waveguide of westerly wind, and hence they tend to be refracted poleward. As a consequence, large amplitude wave events break and dissipate nearer the pole so that the polar vortex is slowed and the polar stratosphere becomes warmer. Conversely, if the QBO is westerly, planetary waves are less latitudinally restricted and their centre of activity moves further away from the pole, leading to a colder and more stable vortex. This 'Holton-Tan relationship' has been shown by several authors not to be statistically robust particularly under solar maximum conditions [Labitzke, 1987; Gray et al., 2001], and during late winter [Naito and Hirota, 1997]. However, Lu et al. [2008] have shown that its reported failure in late winter is likely to be an artefact due to analysis of data at a single pressure level simultaneous with a downward movement of the extra-tropical QBO signal between early and late winter.

[5] Baldwin and Dunkerton [1998] reported on observations of the modulating effect of the QBO on the wintertime Antarctic stratospheric polar vortex. They noted that the vortex is much stronger and longer-lived than its equivalent in the Arctic as planetary waves do not significantly disrupt the Antarctic polar vortex in the lower and middle stratosphere; consequently the QBO was not observed to modulate the vortex strength during midwinter. The QBO was observed to modulate the winds at mid-latitudes from late autumn, but, unlike in the northern hemisphere, this modulation remained restricted to the mid-latitudes through winter and early spring. Nevertheless, they observed the temperature of the southern hemisphere wintertime polar vortex to be slightly colder under westerly than easterly QBO. They found that the southern hemisphere effects were 


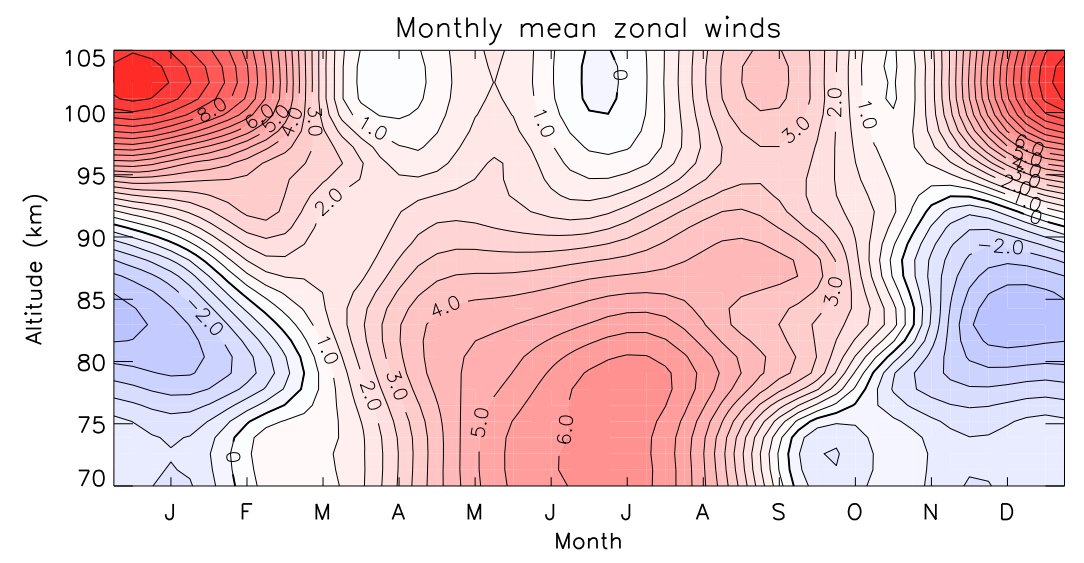

Figure 1. IDI zonal mean wind climatology, eastwards positive with contours at $0.5 \mathrm{~m} / \mathrm{s}$ intervals. The thick black contour represents the zero wind line.

best observed using a QBO pressure level of $25 \mathrm{hPa}$ to define its phase.

[6] In this paper we measure the QBO influence on the winds in the Antarctic mesosphere and lower thermosphere and relate this both to planetary wave dynamics and to published QBO effects on the stratospheric polar vortex. Quantifying the QBO influence is a necessary prerequisite for investigating and quantifying other possible longer-term influences on the mesosphere including the effects of solar variability, ozone loss and recovery, and anthropogenic greenhouse gases.

\section{Analysis}

[7] The analysis presented here utilises data from the imaging Doppler interferometer (IDI) technique [Adams et al., 1985] at Halley where it has been used to measure mesospheric winds nearly continuously between December 1996 and December 2007. The data cover five QBO cycles and a full solar cycle. Its operation at Halley is an adaptation of the NOAA HF radar [Grubb, 1979] and has been described in detail by Jones et al. [1997], Charles and Jones [1999] and Hibbins et al. [2006]. Variations in the refractive index due to ionization irregularities produce independent scattering regions, from each of which a line of sight Doppler velocity is measured. By inclusion of many simultaneously occurring scattering regions in a 3D analysis, three components of the wind are derived, within an altitude range of 50-105 km. However, the lower portion of the IDI range, below $70 \mathrm{~km}$, is noisy and produces a less continuous data series, and so has been excluded from this analysis, as has much of the data from 2002 due to antenna damage. Data are recorded either every 5 or every 15 minutes, and derived wind data are binned into $5 \mathrm{~km}$ altitude ranges. This IDI technique has been validated [Jones et al., 2003] at Bear Lake, Utah, through a direct comparison with a co-located meteor radar.

[8] For this study, hourly mean winds were firstly derived for each $5 \mathrm{~km}$ high altitude bin, from $70-105 \mathrm{~km}$. Following the method of Charles and Jones [1999], to maximise data integrity, wind velocity values for each component scattering region where adequate signals were not received in all eight antenna-pulse combinations were first removed.
Values in excess of $\pm 120 \mathrm{~m} / \mathrm{s}$ were also removed, as these are unlikely to represent valid winds. Tides with periods of 12 and 24 hours were removed from a four day running mean of the data. Monthly averages were then formed for the 12 years of data. These were deseasonalised by subtracting the climatological monthly means from each individual month of data.

\section{Climatologies}

[9] Figure 1 shows the monthly climatological means, as derived above. The strongest zonal winds, up to $10 \mathrm{~m} / \mathrm{s}$, are in the eastwards (positive, red) jet which occurs above $90 \mathrm{~km}$ from November to March in summer. Below this, from $75-90 \mathrm{~km}$ over the same period, is a weaker westwards jet with winds under $4 \mathrm{~m} / \mathrm{s}$. During the wintertime from March to September an extensive eastwards jet occurs below $95 \mathrm{~km}$ extending upwards from the stratospheric vortex region; this persists until October above $80 \mathrm{~km}$. Above $95 \mathrm{~km}$, in the winter months, there are generally much weaker eastwards winds, briefly reversing to weak westwards winds in midwinter. This climatology is in good general agreement with those generated by Hibbins et al. [2006] based on a subset of the data used in this study. It establishes the baseline against which the altitude profile of the effect of the QBO can be investigated (below).

\section{QBO Dependence}

\subsection{Analysis}

[10] To examine the relation between polar mesosphere dynamics and the equatorial stratospheric wind, these two data sets have been cross-correlated. The IDI data used are as described above, and the QBO data are monthly zonally averaged equatorial winds from $50 \mathrm{hPa}$, accessed from NOAA's Climate Prediction Centre; QBO data from $50 \mathrm{hPa}$ were used as this is the reference level widely used by other authors.

[11] We calculate the correlation between Halley data and the equatorial $50 \mathrm{hPa} \mathrm{QBO}$ for lags between 0 and -28 months stepping one month at a time, (thus covering the complete QBO cycle, which averages $\sim 28$ months [e.g., Naujokat, 1986]). A negative lag as used here means that the IDI data is lagging behind the QBO winds. The 95\% 
a) Zonal winds: All months

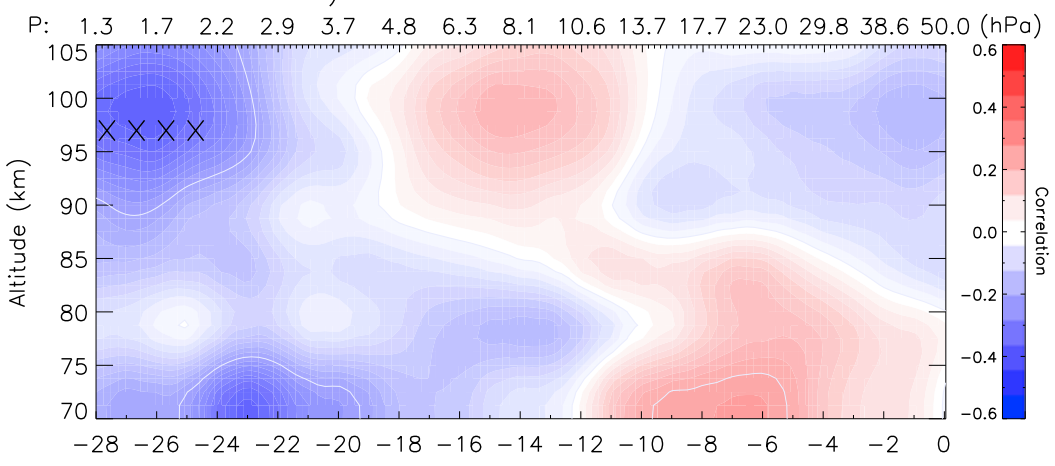

b) Zonal winds: Winters (June,July,Aug)

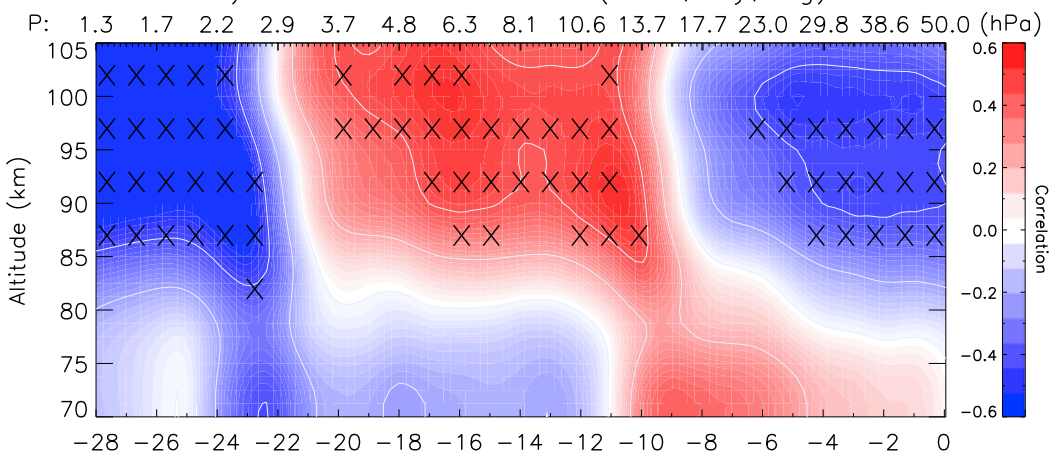

c) Zonal winds: Springs (Sept,Oct,Nov)

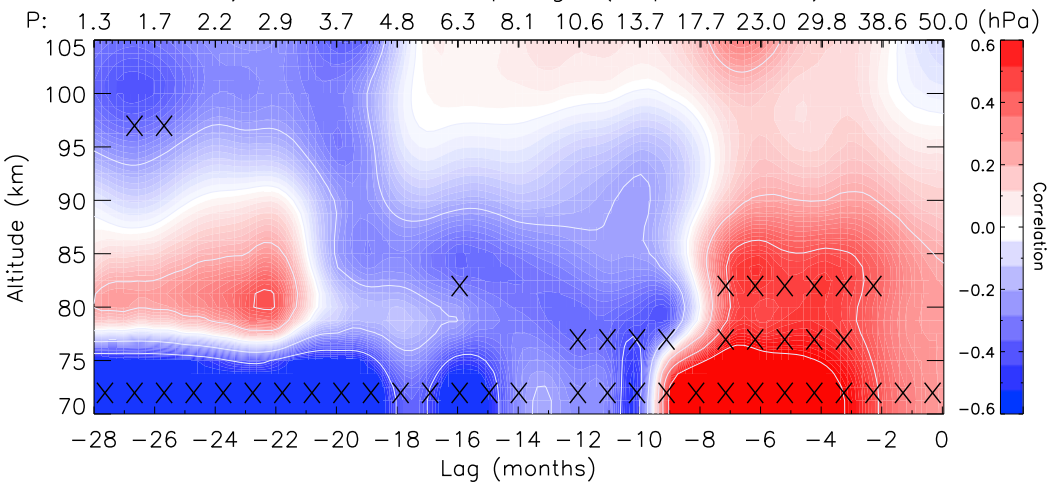

Figure 2. Cross correlations between QBO and mean zonal wind anomalies at each altitude bin for (a) all data, (b) winter months only (June, July, and August) and (c) spring months only (September, October, and November). Crosses show areas above the $95 \%$ confidence level. Grey contour lines are every 0.2 units.

confidence level has been calculated from a Student's T-test for a two-tailed distribution using an effective sample size $\left(N^{\prime}\right)$ to account for the adverse effect on the significance level of any autocorrelation in either of the time series [e.g., Brown, 2008].

[12] Figure 2 shows cross correlations between the observed zonal mean wind anomalies and the QBO at $50 \mathrm{hPa}$, for lags from 0 to -28 months, which are equivalent to approximate QBO pressure levels of 50 to $1.3 \mathrm{hPa}$ respectively. The near-linear relationship between the phase of the QBO and log pressure level was calculated by Baldwin and Dunkerton [1998], who showed that a phase difference, or lag, is equivalent to defining the QBO from a different pressure level. They used NCEP global data from 1000 to $1 \mathrm{hPa}$ at the equator to determine the phase where the correlation with the $\mathrm{QBO}$ at various pressure levels max- imises. They found the difference in phase between maximum correlations between $50 \mathrm{hPa}$ (as used here) and $10 \mathrm{hPa}$ to be $151^{\circ}$ at the equator. Taking an average QBO cycle period of 28 months, this corresponds to an 11.8 month lag. Assuming a linear relationship between log pressure and QBO phase, pressure levels derived in this way are shown on the top axes of Figure 2 for comparison with the lag in months on the bottom axes.

[13] In Figure 2a the whole dataset is considered. No statistically significant correlation above the 95\% confidence level is seen for any IDI data altitude or QBO lag, except for at long lags at $95 \mathrm{~km}$. However, when seasonal subsets of the data are considered, areas of statistically significant correlation become evident as indicated in Figure 2 by black crosses. This is particularly the case for winter (Figure 2b) and spring (Figure 2c) discussed below. 

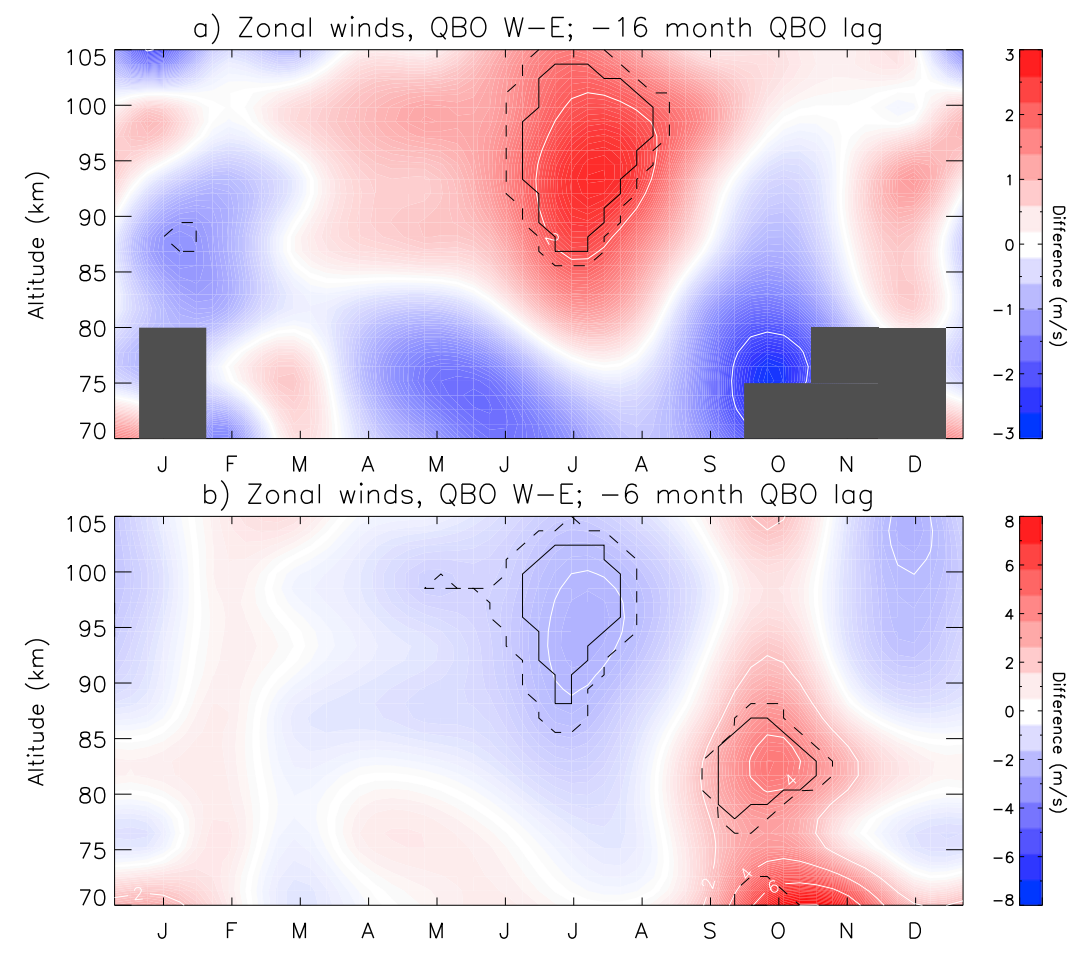

Figure 3. Zonal wind difference climatologies (QBO westerly minus easterly data) for (a) using a -16 month lag; (b) using a -6 month lag in the QBO data. Contour lines are shown every $2 \mathrm{~m} / \mathrm{s}$, and blanked out areas have no data available for one or both phases of the QBO. The dashed and solid contours represent levels of 90 and $95 \%$ confidence respectively.

\subsection{Winter}

[14] In winter (Figure 2b), strong correlations are observed between 85 and $105 \mathrm{~km}$ altitude, with many regions of the plot above the $95 \%$ confidence level. There is a region of anti-correlation above $\sim 85 \mathrm{~km}$ for lags from 0 to -8 months, which peaks between 95 and $100 \mathrm{~km}$ altitude, where it exceeds the $95 \%$ confidence level. This range of lags corresponds to a $\mathrm{QBO}$ pressure level of $50 \mathrm{hPa}$ up to approximately $15 \mathrm{hPa}$. Above this, for pressure levels corresponding to the $\mathrm{QBO}$ from 15 to $3 \mathrm{hPa}(-9$ to -21 months lag) the correlation is positive, again maximising at $95-100 \mathrm{~km}$, with correlation coefficients of about 0.5 . Further above this pressure level the correlation turns negative again, reaching the $95 \%$ confidence level above $\sim 2 \mathrm{hPa}$ from $90-105 \mathrm{~km}$. This corresponds to lags of between -24 and -28 months and the correlation reaches -0.54 in this region. It should be noted that stronger correlations and higher levels of confidence are likely to preferentially exist at the higher IDI sampling altitudes because this is where the IDI technique inherently achieves considerably better data coverage [Hibbins et al., 2006].

[15] The centre of the region of positive correlation occurs at a lag of approximately -16 months which is equivalent to correlating the IDI winds with the equatorial QBO at a pressure level of about $7 \mathrm{hPa}$. This is in good agreement with the pressure level of $10 \mathrm{hPa}$ found by Espy et al. [1997] and $5 \mathrm{hPa}$ by Hibbins et al. [2007] to be optimum for QBO-related modulations in the summertime polar mesosphere. This lag of -16 months has therefore been used here to determine the magnitude of the wintertime QBO related effect in the winds.
[16] Figure 3a shows the difference climatology between westerly and easterly QBO conditions with a lag of -16 months; a three month data window is used. The gray regions indicate month-altitude combinations where there was insufficient data to derive a value due to the low number of data points from the maximum 12 years of data. The dashed lines indicate regions where the difference is greater than the $90 \%$ confidence level, as determined from a Monte Carlo approach taking the distribution generated by randomly binning the data 1000 times. The solid line regions are the same for the $95 \%$ confidence level.

[17] As would be expected from the region of statistically significant strong positive correlations at -16 months lag from Figure $2 b$, Figure $3 a$ shows a positive difference between westerly and easterly QBO in winter, above $85 \mathrm{~km}$. This difference peaks at $2.6 \mathrm{~m} / \mathrm{s}$ in July. When the QBO at $5 \mathrm{hPa}$ (equivalent to -16 months lag) is westerly, planetary waves formed in the winter hemisphere can propagate through the equatorial MQBO gate [Hibbins et al., 2007] to the summer hemisphere. This will result in less planetary wave activity in the winter polar mesosphere, and consequently a stronger vortex in the mesosphere. This is seen in the stronger westerly mesospheric wind anomalies at Halley as shown in Figure 3a.

[18] However, when the MQBO is in the westerly phase, the stratospheric QBO is easterly [Baldwin et al., 2001]. Under easterly QBO conditions in the equatorial stratosphere, planetary waves formed in the winter hemisphere are deflected away from the equator, and so remain trapped in the winter hemisphere stratosphere. This will result in a weaker polar vortex as it is disrupted by planetary wave 
activity; this is the Holton-Tan effect. Thus, in winter, the correlation between MQBO and winds will tend to be opposite in the stratosphere to that in the MLT. Figure $2 \mathrm{~b}$ suggests the presence of this effect, and with a reversal in correlation below $\sim 80 \mathrm{~km}$. Comparison with Figure 1 shows the QBO dependence of the wind in the upper mesosphere (up to $2.6 \mathrm{~m} / \mathrm{s}$ ) is large compared with the background climatological mean.

\subsection{Spring}

[19] Figure 2c shows correlations for the austral spring. There is an area of strong positive correlation (up to 0.54) for lags between -2 and -8 months and for altitudes between $70 \mathrm{~km}$ and $90 \mathrm{~km}$ which is consistently above the $95 \%$ confidence level. There is only weak evidence for areas of statistically significant correlation at other altitudes and lags.

[20] These data indicate that, in spring, there is an eastward enhancement of the winds under westerly QBO, where the QBO phase is determined at $\sim 25 \mathrm{hPa}$ (equivalent to a lag of -6 months). This agrees closely with the observations by Baldwin and Dunkerton [1998] who used NCEP assimilative data in the southern hemisphere stratosphere. They found that in the upper stratosphere (at $5 \mathrm{hPa}$ ) there was a strong difference climatology (QBO westerlyeasterly) centred on $\sim 70^{\circ} \mathrm{S}$ in November; this difference reached $10 \mathrm{~m} / \mathrm{s}$ (i.e. the wind was more eastward during westerly QBO). They found that $25 \mathrm{hPa}$ was the best reference pressure level when calculating QBO phase; this matches the lag for the region of highest correlation with the IDI data in Figure $2 b$.

[21] Baldwin and Dunkerton [1998] noted that November coincided with the final break up of the polar vortex and argued that the vortex was then weak enough to show a response to the QBO dependence of the planetary waves. Figure $3 \mathrm{~b}$ shows the difference climatology, in the same manner as for Figure $3 \mathrm{a}$, but for a lag of -6 months, which corresponds to a QBO pressure level of $25 \mathrm{hPa}$. This difference peaks at $7.6 \mathrm{~m} / \mathrm{s}$ in November, at $70 \mathrm{~km}$, and extends through the mesosphere with confidence levels greater than $95 \%$ from $80-90 \mathrm{~km}$. The peak above $80 \mathrm{~km}$ is nearer October, and as the vortex in the mesosphere is inherently weaker than in the stratosphere, may therefore be susceptible to planetary wave action at an earlier date.

[22] It should also be noted that Hibbins et al. [2009] have demonstrated that planetary waves can reach the Antarctic mesosphere in summer from the opposite (winter) hemisphere depending upon the phase of the MQBO. If the equatorial $\mathrm{QBO}$ at $25 \mathrm{hPa}$ is westerly, then the $\mathrm{MQBO}$ will be easterly [Baldwin et al., 2001]. This will mean that planetary waves are blocked from propagating across the equator and thus the vortex in the mesosphere will remain more stable with a stronger westerly wind (Figure 3b). Therefore, in spring, the westerly equatorial QBO in the stratosphere and the simultaneous easterly MQBO will act in the same sense regarding the stability of the vortex. This is the converse of the situation in winter, as discussed above, when they will act in the opposite sense.

\section{Summary}

[23] Data from the Imaging Doppler Interferometer at Halley over a 12 year period are used to investigate the link between Antarctic mesospheric winds and the equatorial stratosphere through the QBO.

[24] During the winter months, westerly winds extend upwards from the polar vortex into the mesosphere to $90 \mathrm{~km}$ and show a clear correlation, above the $95 \%$ confidence level, with the equatorial QBO from $50 \mathrm{hPa}$. This correlation maximises between 85 and $105 \mathrm{~km}$ at a lag of $16 \pm$ 4 months, with the mesospheric wind data preceding the QBO data; this is equivalent to the MQBO. The difference climatology quantifies this effect for the zonal wind anomalies and shows that it maximises between June and August above $85 \mathrm{~km}$, with a difference of up to $2.6 \mathrm{~m} / \mathrm{s}$ between westerly and easterly MQBO phases.

[25] In spring, correlations maximise in the mesosphere at lags of -6 months, equivalent to the stratospheric QBO at $\sim 25 \mathrm{hPa}$. They also show an eastward enhancement of polar mesospheric wind anomalies but under westerly stratospheric QBO.

[26] The observations support the hypothesis that the winds are modulated by action of the equatorial QBO on planetary wave propagation. In winter, a westerly MQBO will allow mesospheric planetary waves to cross the equator to the opposite hemisphere, thus reducing the mesospheric planetary wave activity so that the vortex-related winds in the mesosphere will be stronger. The simultaneous easterly QBO in the stratosphere will increase stratospheric planetary wave activity so that the vortex in the stratosphere will weaken - this stratospheric signature is the Holton-Tan effect. In spring however, a westerly stratospheric QBO will decrease polar stratospheric planetary wave activity and strengthen the winds in the stratosphere. The simultaneous easterly MQBO will also reduce mesospheric planetary wave activity because the waves will be blocked from crossing from the opposite (autumn) hemisphere. Hence the mesospheric winds will also be strengthened.

[27] Acknowledgments. This work was funded under the UK Natural Environment Research Council consortium grant SOLCLI (NE/D002753/1). The engineers and data managers at the British Antarctic Survey are thanked for the maintenance of the IDI. QBO data are courtesy of the National Centers for Environmental Prediction (NCEP).

\section{References}

Adams, G. W., D. P. Edwards, and J. W. Brosnahan (1985), The imaging Doppler interferometer: Data analysis, Radio Sci., 20, 1481-1492, doi:10.1029/RS020i006p01481.

Baldwin, M. P., and T. J. Dunkerton (1998), Quasi-biennial modulation of the Southern Hemisphere stratospheric polar vortex, Geophys. Res. Lett., 25, 3343-3346, doi:10.1029/98GL02445.

Baldwin, M. P., et al. (2001), The Quasi-Biennial Oscillation, Rev. Geophys., 39, 179-229, doi:10.1029/1999RG000073.

Baumgaertner, A. J. G., A. J. McDonald, G. J. Fraser, and G. E. Plank (2005), Long-term observations of mean winds and tides in the upper mesosphere and lower thermosphere above Scott Base, Antarctica, J. Atmos. Sol. Terr. Phys., 67, 1480-1496, doi:10.1016/j.jastp.2005.07.018. Brown, B. H. (2008), Short-term changes in global cloud cover and in cosmic radiation, J. Atmos. Sol. Terr. Phys., 70, 1122-1131, doi:10.1016/j.jastp.2008.02.003.

Burrage, M. D., R. A. Vincent, H. G. Mayr, W. R. Skinner, N. F. Arnold, and P. B. Hays (1996), Long-term variability in the equatorial middle atmosphere zonal wind, J. Geophys. Res., 101, 12,847-12,854, doi:10.1029/96JD00575.

Charles, K., and G. O. L. Jones (1999), Mesospheric mean winds and tides observed by the imaging Doppler interferometer (IDI) at Halley, Antarctica, J. Atmos. Sol. Terr. Phys., 61, 351-362, doi:10.1016/S1364-6826(98)00156-4.

Dunkerton, T. J., and M. P. Baldwin (1991), Quasi-biennial modulation of planetary-wave fluxes in the Northern-Hemisphere winter, J. Atmos. Sci., 48, 1043-1061, doi:10.1175/1520-0469(1991)048<1043:QBMOPW> 2.0.CO;2. 
Espy, P. J., J. Stegman, and G. Witt (1997), Interannual variations of the quasi-16-day oscillation in the polar summer mesospheric temperature, J. Geophys. Res., 102, 1983-1990, doi:10.1029/96JD02717.

Gray, L. J., S. J. Phipps, T. J. Dunkerton, M. P. Baldwin, E. F. Drysdale, and M. R. Allen (2001), A data study of the influence of the equatorial upper stratosphere on northern-hemisphere stratospheric sudden warmings, Q. J. R. Meteorol. Soc., 127, 1985-2003, doi:10.1002/qj.49712757607.

Grubb, R. N. (1979), The NOAA SEL HF radar system (ionospheric sounder), NOAA Tech. Memo. ERL SEL-55, NOAA, Boulder, Colo.

Hibbins, R. E., P. J. Espy, and M. J. Jarvis (2006), Mean winds and tides in the mesosphere and lower thermosphere above Halley, Antarctica, J. Atmos. Sol. Terr. Phys., 68, 436-444, doi:10.1016/j.jastp.2005.02.030.

Hibbins, R. E., P. J. Espy, and M. J. Jarvis (2007), Quasi-biennial modulation of the semidiurnal tide in the upper mesosphere above Halley, Antarctica, Geophys. Res. Lett., 34, L21804, doi:10.1029/2007GL031282.

Hibbins, R. E., M. J. Jarvis, and E. A. K. Ford (2009), QBO influence on long-period planetary waves in the Antarctic upper mesosphere, J. Geophys. Res., 114, D09109, doi:10.1029/2008JD011174.

Holton, J. R., and H. C. Tan (1980), The Influence of the equatorial QuasiBiennial Oscillation on the global circulation at $50 \mathrm{Mb}$, J. Atmos. Sci., 37 2200-2208, doi:10.1175/1520-0469(1980)037<2200:TIOTEQ $>2.0$. $\mathrm{CO} ; 2$.

Jacobi, C., R. Schminder, and D. Kürschner (1996), On the influence of the stratospheric quasi-biennial oscillation on the mesopause zonal wind over central Europe, Meteorol. Z., 5, 318-323.
Jones, G. O. L., K. Charles, and M. J. Jarvis (1997), First mesospheric observations using an imaging Doppler interferometer adaptation of the dynasonde at Halley, Antarctica, Radio Sci., 32, 2109-2122, doi:10.1029/ 97RS01825

Jones, G. O. L., F. T. Berkey, C. S. Fish, W. K. Hocking, and M. J. Taylor (2003), Validation of imaging Doppler interferometer winds using meteor radar, Geophys. Res. Lett., 30(14), 1743, doi:10.1029/2003GL017645.

Labitzke, K. (1987), Sunspots, the QBO, and the stratospheric temperature in the north-polar region, Geophys. Res. Lett., 14, 535-537, doi:10.1029/ GL014i005p00535.

Lu, H., M. P. Baldwin, L. J. Gray, and M. J. Jarvis (2008), Decadal-scale changes in the effect of the QBO on the northern stratospheric polar vortex, J. Geophys. Res., 113, D10114, doi:10.1029/2007JD009647.

Naito, Y., and I. Hirota (1997), Interannual variability of the northern winter stratospheric circulation related to the QBO and the solar cycle, J. Meteorol. Soc. Jpn., 75, 925-937.

Naujokat, B. (1986), An update of the observed Quasi-Biennial Oscillation of the stratospheric winds over the Tropics, J. Atmos. Sci., 43, $1873-$ 1880, doi:10.1175/1520-0469(1986)043<1873:AUOTOQ >2.0.CO;2.

E. Ford, R. E. Hibbins, and M. J. Jarvis, British Antarctic Survey, High Cross, Madingley Rd., Cambridge CB3 0ET, UK. (eakf@bas.ac.uk) 